\title{
The Structural Model of Organization Performance in Small and Medium Enterprises in Thailand Medium Enterprises in Thailand
}

\author{
Thawatchai Nima $^{a}$, Banterng Sriard ${ }^{b}$, Pattarapon Chummee ${ }^{c}$, Pornthep Kaewchur ${ }^{d}$ \\ ${ }^{\mathbf{a}, \mathbf{b}}$ Independent Researcher, Thailand. \\ ${ }^{\mathbf{c}}$ Valaya Alongkorn Rajabhat under the Royal Patronage University, Thailand. \\ ${ }^{d}$ Rajamangala University of Technology Suvarnabhumi, Thailand

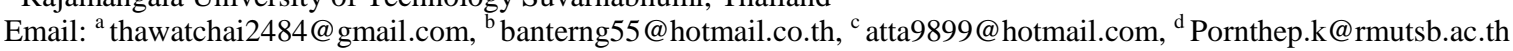

Article History: Received: 10 January 2021; Revised: 12 February 2021; Accepted: 27 March 2021; Published online: 20 April 2021

\begin{abstract}
This research aimed to 1. Study factors of supplier quality management and production quality management that affect organization performance.2. Confirm the structural models that affect organization performance. This study was mixed methods research. The quantitative research consisted of 13 observable variables, which collected data from 260 medium and small companies in Thailand. The qualitative research collected data from a focus group of experts involved in organizational management, quality management, and supplier management of nine experts. The research results were found that 1 . The structural model of organization performance in Small and Medium Enterprises in Thailand were consistent and harmonious with empirical data, with consistency values of $\chi 2=94.89, \mathrm{df}=61, \chi 2 / \mathrm{df}=1.56, \mathrm{CFI}=0.98$, GFI $=0.95, \mathrm{SRMR}=0.049$, RMSEA $=0.046$. 2. Factors affecting organization performance are factors of Supplier Quality Management, and Production Quality Management, respectively.
\end{abstract}

Keywords: Supplier Quality Management, Production Quality Management, Organization Performance

\section{Introduction}

Organization Performance (OP). Nowadays, every organization, both small and large, must develop and create the organization to have good performance. The organization performance of an organization is either good or bad, not only from development within the company itself. Organizations may rely on good business partners [1] such as having good suppliers, good relationships and being able to help each other when demand is uncertain, or having a company that can assist in production that helped with production in case our company fails to produce etc. Since there are many SMEs in the present, each company needs to have a good organization performance that can reduce costs and profit for the company to survive and gain more market share. On the other hand, within our company we have to improve the quality of our products and services in order to make our customers satisfied with our company. Production quality management was a combination of management from management, production management optimization, production planning, relationship [2] between production departments in each department, as well as organizational development through training employees to be able to produce products to meet the required quality standards.

Therefore, proper organization performance should study internal influences, namely Production Quality Management (PQM) and external influenced Supplier Quality Management (SQM) in order to be able to measure organization performance appropriately and with varying degrees. Therefore, the researcher has studied the factors of Production Quality Management and Supplier Quality Management that influence organization performance to guide the development of supplier quality management and production quality management.

\section{Research Objectives}

1. Study factors of supplier quality management and production quality management that affect organization performance.

2. Confirm the structural models that affect organization performance.

\section{Literature Review}

Producing quality products now requires good quality raw materials. In Thailand, there are many SMEs emerging to manufacture products and produce various parts to feed the big industry. Therefore, developing organizations or SMEs to have quality, able to produce products are required. What is indispensable is to have a 
good organization performance that can help businesses survive in the current environment. Small and Medium Enterprises in Thailand have divided Small and Medium Enterprises (SMEs) in Manufacturing in 3 categories. These included Micro businesses employed no more than 5 people and earned no more than 1.8 million baht per year. Small businesses employed more than 50 people and earned not more than 100 million baht per year. Medium enterprises employed no more than 200 people and earned not more than 500 million baht per year. Small and Medium Enterprises (SMEs) account for $35.30 \%$ of gross domestic product, which was one third of the GDP of Thailand [3]. Supporting SMEs to have good organization performance will further increase the GDP of Thailand.

\subsection{Supplier Quality Management}

The suppliers [4,5] were a person or company that delivers goods or raw materials to the next level of manufacturing companies. TD suppliers are suppliers that are ready to deliver goods [6], quality raw materials, on time [7]. There may be a number of trusted and reliable suppliers to have, but the right supplier may be selected at the right time. A good supplier to suit the supplier company can effectively support our manufacturing processes. Having a good and suitable supplier for the company means that the company does not have to hold large volumes of inventory, which reduces the cost of managing its inventory. The raw materials can be delivered within the specified time and quantity. Hence, having a reliable supplier will directly affect the inventory volume. Good supplier management impacts inventory and production processes, because with good suppliers, they can support the company's raw materials, products, and services according to the company's needs. In accordance with [8] supplier management, it is the management of the manufacturer of the product or the person who supplies the raw material to the company for production in order to optimize performance in terms of price, quality, delivery times. From the above research, the factors related to Supplier Quality Management can be summarized as follows: 1 . Relationship between suppliers and manufacturers 2 . Price management 3 . Quality of products and services 4. Delivery time

\subsection{Production Quality Management}

Production Quality Management is the quality production management where quality is largely dependent on the customer who is responsible for most SMEs who have to follow the systems that the customer company has implemented in their production [7, 9, 10]. For example, the Total Quality Management (TQM) system is a system that emphasizes quality in production with an emphasis on organizational participation. The TQM system is also focused on the entire organization, but at the supervisor level to the operational level so that the company can produce products or services according to the standards set by the company or customers, including SMEs in Thailand [11]. At present, TQM systems have been applied to suit the company's context. Another indispensable system for quality control is ISO9000, which is a quality control system. Bringing raw materials into production to delivering products to customers has long been a system that is familiar to Thai SMEs, which has been adapted and applied in work to meet the needs of customers. The quality of production can be summarized into 6 factors as follows: 1. Top management in management, control and leadership in quality management within the organization. 2. Process management is the management of the production process to be able to control the quality at every step and can check the quality in every step of the production. 3. Quality data reporting is an important factor, since the collection of production quality data, good data collection that can be used for various purposes for analysis is important, including traceability of the non-quality products from the manufacturing period or what is the cause of the poor-quality products? 4. Employee relationship is a relationship between employees with each other because most of the work must work as a team, especially the TQM system, have to set up a team that acts on the quality of the product and must serve to distribute responsibility in the production of the product Quality for the entire organization. 5. Customer Relationship is the relationship between the manufacturer and the customer in order to be able to produce products that meet the needs of the customers. Therefore, having a relationship may not only be a matter of product quality, but may affect business operations as a long-term partner. 6. Training is to train employees to understand the quality of products and services so that employees are aware of the production of quality products $[1,2,7,10,12,13]$.

\subsection{Organization performance.}

Nowadays, whether an organization will survive in its present conditions is an important issue. Performance Measurement has several methods of measuring current performance [14]. This is the measurement of customer satisfaction because the customer is satisfied with the product or service will affect the sales and revenue further, 
the measurement of the profit generated from the operation, the measurement of sales growth compared to the past, the measure of increased market share. Measuring results in SMEs should be simple and measurable by the organization itself. From the above research, the factors related to organization performance can be summarized in 3 aspects: 1. Cost Performance 2. Profitability 3. Market share [15-19].

\subsection{Supplier Quality Management and Production Quality Management.}

Production Quality Management. One thing that is indispensable is having a company that supplies raw materials, delivers good source products to them so that they can continue to produce good products or services [1]. Having a good supplier means that the company is not afraid that there will be no raw materials in production, but a good quality supplier will help plan the raw material requirements or help with the support Keeping inventory to help the company reduce the cost of managing inventory or stock. Choosing a supplier is also involved in the production management, because the same raw materials, the same quality, may be available in many companies, so choosing the right supplier for the time period may result in cost savings [4, 8, 9, 12, 20-23]. Therefore, supplier quality management affects the production quality management.

$\mathrm{H}_{1}$ Supplier Quality Management Influences Production Quality Management.

\subsection{Supplier Quality Management and Organization performance}

Supplier Quality Management is the arrangement for the suppliers or the person who will send the products to the manufacturing company, so suppliers contribute a lot to organization performance because the performance of most organizations is a focus on cost efficiency. Therefore, having a quality supplier with a reasonable price can help reduce production costs and increase profitability. A good supplier must have a good relationship with the organization and not bring any trade secrets to its competitors because it will enable the competitor to have more competitiveness which will directly affect the company's market share. Having a good supplier must be able to support both the mold that the company can compete and have quality products. Therefore, supplier quality management is an integral part of organization performance [5, 8, 24-26].

$\mathrm{H}_{2}$ Supplier Quality Management Influences Organization performance.

\subsection{Production Quality Management and Organization performance}

Production Quality Management is the quality management of production because the production depends on your quality factors both in terms of quality production, management from effective supervisors. Reporting various data in production so that the company can produce quality products, so the production management can directly affect the company's performance. For example, cost performance, if quality products are produced, the company will not have to cost many times for production or the cost of handling the product of the manufacturer $[1,15,27]$ and also affect the profitability of the organization. Therefore, quality production directly or indirectly affects organization performance $[1,9,15,19,28]$.

$\mathrm{H}_{3}$ Production Quality Management influences organization performance.

Research variables can be summarized as follows: 1.Supplier Quality Management (SQM) 1.1.SupplierSupplier Relationship (SQM1) 1.2. Price Management (SQM2) 1.3. Quality of Products and Services (SQM3) 1.4. Delivery time (SQM4)2. Production Quality Management(PQM) 2.1Top management (PQM1) 2.2. Process management (PQM2) 2.3. Quality data reporting (PQM3)2.4. Employee relationship (PQM4) 2.5. Customer Relationship (PQM5)2.6Training (PQM6) 3. Organization performance (OP) 3.1. Cost Performance (OP1) 3.2. Profitability (OP2) 3.3. Market share (OP3) and can show Concept model as Figure 1.

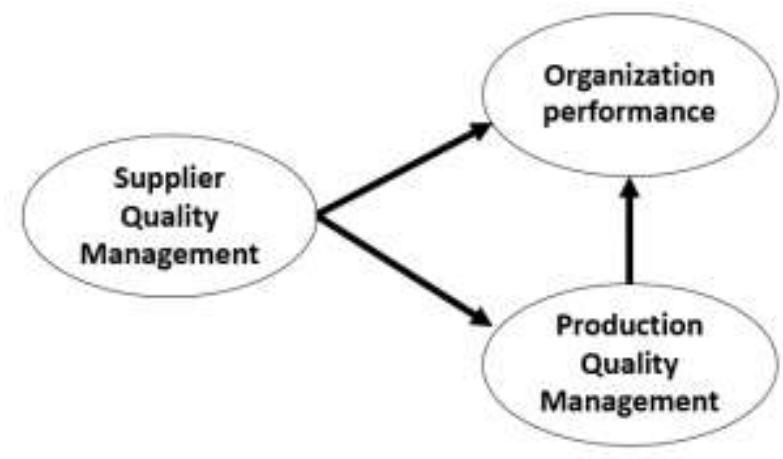

Figure 1.Concept mode 


\section{Research Methods}

This research is a combination of quantitative research that collected 260 data samples from 517,899 SMEs in Thailand [3] due to 13 observable variables [29] from the SMEs industry group in the manufacturing sector of Thailand with a convenient randomization method. The tool was used as a closed-ended questionnaire with a Likert scale 5-level scoring, with an IOC of 0.8-1.00, and a Cronbach's alpha value of 0.811. The distribution of questionnaires were manually and electronically. Qualitative research was a focus group of nine experts working in quality management or in-house supplier management by selecting experts using the judgment sampling. The criteria are supervisor level or above and have at least 10 years of working experience in quality management or supplier management as a validation of the model derived from quantitative research.

\section{Research Results}

Research results from 260 SMEs data collection were 16 micro businesses or $6.15 \%, 237$ small businesses or 91.15\%, 7 medium enterprises or $2.70 \%$. Structural Equation Analysis (SEM). From the analysis of the model, 3 latent and 13 observable variables were found. The interpretation of the results by Lisrel confirmed the consistency of the empirical data collected with the questionnaire model to be consistent and harmonious. The results showed that $\chi^{2} 2=94.89, \mathrm{df}=61, \chi^{2} / \mathrm{df}=1.56, \mathrm{CFI}=0.98, \mathrm{GFI}=0.95, \mathrm{SRMR}=0.049, \mathrm{RMSEA}=0.046$, passed the criterion of [29] and had a predictive coefficient of $R^{2}$ at $67 \%$ as shown in Figure 2.

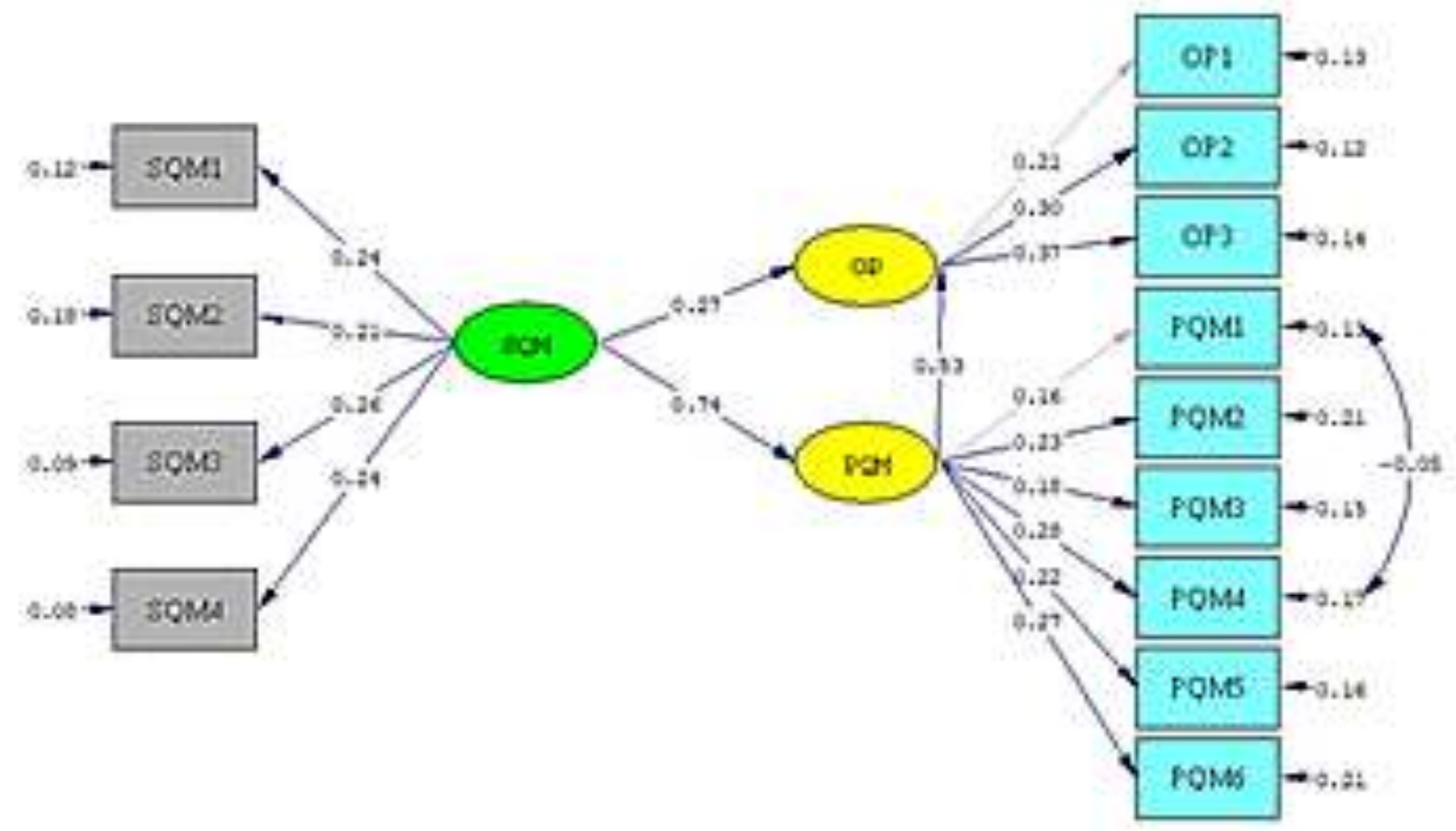

Figure 2 Causal models affecting organization performance

From Figure 2, it was found that the causal model affecting organization performance was consistent and harmonious with the empirical data according to the criteria of [29] and had the total effect as shown in Table 1.

Table 1 showed the total effect of each influence relationship

\begin{tabular}{|l|l|l|l|l|}
\hline Hypothesis & Direct Effect & Indirect Effect & Total Effect & Decision \\
\hline $\begin{array}{l}\mathrm{H}_{1} \text { Supplier Quality Management Influence } \\
\text { Production Quality Management }\end{array}$ & 0.740 & - & 0.740 & Accepted \\
\hline $\begin{array}{l}\mathrm{H}_{2} \text { Supplier Quality Management Influence } \\
\text { Organization performance }\end{array}$ & 0.270 & 0.392 & 0.662 & Accepted \\
\hline $\begin{array}{l}\mathrm{H}_{3} \text { Production Quality Management Influence } \\
\text { Organization performance }\end{array}$ & 0.530 & - & 0.530 & Accepted \\
\hline
\end{tabular}


From Table 1, there were 3 hypotheses and all 3 hypotheses with descending influence as follows: 1 . H1 Supplier quality management influenced production quality management with 0.740 influence that were 0.740 direct influence, and No Indirect Influence. 2. H2 Supplier quality management influenced organization performance with 0.662 influence, divided into 0.270 direct influence, and 0.392 indirect influence. 3 . H3 Production quality management influenced organization performance with 0.530 influence, divided into 0.530 direct influence, no indirect influence.

The qualitative research was a focus group of nine experts from experts working in quality management or inhouse supplier management to validate empirical models. The focus group results were in the same direction, which was to agree with the aforementioned models because the production of quality products must start from upstream, that was good raw materials obtained from suppliers who were good at handling quality raw materials. Medium water was the production of quality. If there is good quality control during the production process, then it will be able to produce good products that meet the needs of customers. The production process required cooperation throughout the organization from the supervisor level down to the operational level in order to obtain quality products, but all experts were also focused on ensuring the company's relationship with customers and the relationship between company and supplier, because synchronization and sharing of information can reduce production costs and increase organizational efficiency

\section{Discussions Conclusion}

This research was a study to determine the structural models that affected organization performance. This research was a mixed method research by studying the factors of supplier quality management and production quality management that influence organization performance.

Supplier quality management influenced production quality management because the quality production requires quality raw materials. It was consistent with the research of [1]. Quality production required quality raw materials sourced from qualified suppliers, selected by manufacturers. Quality suppliers had the highest direct influence on production quality because of their strong relationship. This was consistent with the research of [2, 4, $21,24]$, because manufacturers will have quality suppliers to deliver raw materials, there must also be a selection criterion for suppliers that are suitable for each SMEs. Suppliers in Thailand that manufacture parts for large companies were mostly SMEs. Most SMEs had a production system that was directed by the customer's company. For example, SMEs did not have ISO9000 standard, but customers who received products from SMEs would help to produce products that met the standard of ISO9000 in order to meet the quality standards set by customers.

Supplierqualitymanagementinfluenced organization performance because a good supplier of quality must deliver raw materials at reasonable prices and at a fraction of the cost of other suppliers. The price of raw materials was also an important factor in selecting a supplier because organization performance needed to have an efficient production cost or the lowest cost in order to maximize profit. This was consistent with the research of $[1,19,27,30]$, and when there was an organization performance that was efficient or low-cost that can be competitive, it would affect the larger market share, respectively.

It also had an indirect influence on organization performance, which is an indirect influence on quality production. Due to having a good supplier and delivering products that met quality standards, quality production also resulted in lower costs. Production quality management had an influence on organization performance because quality production controlled the entire production process from upstream to downstream. Therefore, quality production can reduce production costs and directly affect organization performance. This was consistent with the research of $[1,11,19,31]$, where quality production can also influence market share in the future. Due to the quality of the products, customers would order larger quantities and tell the same industry to buy products from companies that had production quality and can dominate the market, respectively.

The research has found a relationship that was the relationship between supplier quality management that influences the production quality management and organization performance of SMEs in Thailand because most SMEs in Thailand were suppliers who supplied products to large manufacturing companies to use to assemble products. Therefore, Thai SMEs should be encouraged to develop organizations in all four areas: 1. Quality of products and services, 2. Relationship between supplier and manufacturer, 3. Delivery time, and 4. Price management, respectively 


\section{Suggestions}

1. Further research should increase relevant variables in the study of SMEs in Thailand, such as variables in government support, competitiveness variables, knowledge-building variables, etc.

2. This research did not categorize research SMEs. The further research should be compared between micro, small, and medium businesses to make the research more complete.

\section{References}

C. Lin, W. S. Chow, C. N. Madu, C.-H. Kuei, and P. Pei Yu, "A structural equation model of supply chain quality management and organizational performance," International Journal of Production Economics, vol. 96, pp. $355-365,2005$

Y. Lin, B. Liang, and X. Zhu, "The effect of inventory performance on product quality," International Journal of Quality \& Reliability Management, vol. 35, pp. 2227-2247, 2018.

Office of the National Economic and Social Development Council, "THAILAND’S LOGISTICS REPORT 2019," Office of the National Economic and Social Development Council2020.

D. Abdolnaser, O. Hway-Boon, and M. Govindan, "Supplier Development Activities and Buying Firm's Performance: An Empirical Investigation of Iranian SMEs," Iranian Journal of Management Studies, vol. 12, pp. 405-424, Summer 20192019.

A. K. W. Lau, "Supplier and customer involvement on new product performance," Industrial Management \& Data Systems, vol. 111, pp. 910-942, 2011.

A. H. Niknamfar, "Multi-objective production-distribution planning based on vendor-managed inventory strategy in a supply chain," Industrial Management \& Data Systems, vol. 115, pp. 1086-1112, 2015.

G. A. Marodin, G. L. Tortorella, A. G. Frank, and M. Godinho Filho, "The moderating effect of Lean supply chain management on the impact of Lean shop floor practices on quality and inventory," Supply Chain Management: An International Journal, vol. 22, pp. 473-485, 2017.

K. Pornthep, S. Theathanick, and K. Kanreutai, "Supplier Management Factors Affecting Inventory in Small and Medium-sized Electronics and Electrical Parts Manufacturers," Journal of Business, Economics and Communications, vol. 15, pp. 83-98, 2020.

K. Baird, H. K. Jia, and R. Reeve, "The relationships between organizational culture, total quality management practices and operational performance," International Journal of Operations \& Production Management, vol. 31, pp. 789-814, 2011.

V. Leopoulos and G. Chatzistelios, "Quality management systems development based on a production systems taxonomy," The TQM Journal, vol. 26, pp. 215-229, 2014.

S. Teeradej, S. Chaianun, K. Waranon, and C. Sukhumpong, "Total Quality Management in Modern Organizationsby Using Participation and Teamwork," Journalof Arts Management, vol. 4, pp. 818-829, 2020.

I. Milosevic, A. Trajkovic, T. Rajic, D. Nikolic, and S. Arsic, "The effects of quality certification in establishing and developing customer: Supplier relationships," Serbian Journal of Management, vol. 13, pp. 115-131, 2018.

Praneeth Juvvi, Moorthy Karthika Selvi, and Sukumar Debnath, "Effect of vacuum frying on quality attributes of pear (Pyrus communis L) chips and blended oil," Journal of Food Processing and Preservation, vol. 44, 2020.

H. G. Mohamad, N. A. Mehrdad, N. Salman, and N. Ali, "Investigating the Influence of Knowledge Management Practices on Organizational Performance: An Empirical Study," Acta Polytechnica Hungarica vol. 10, pp. 205-216, 2013.

S. Roy, B. Ramudu, I. J. M. v. d. H. Beatrice, and F. Mark, " Organizational climate for innovation and organizational performance: The mediating effect of innovative work behavior," Journal of Vocational Behavior vol. 100, pp. 67-77, 2017.

C. Taejun and K. Russell, "Managing knowledge performance: testing the components of a knowledge management system on organizational," Asia Pacific Educ, vol. 2014, pp. 313-327, 2014.

A. Imran, U. R. Kashif, I. A. Syed, Y. Jamil, and Z. Maria, "Corporate social responsibility influences, employee commitment and organizational performance," African Journal of Business Management, vol. 4, pp. 27962801, 2010.

F. Kiarash, M. M. D. Seyed, A. B. Tatiana, V. S. Natalia, V. N. Yulia, A. G. Svetlana, et al., "The Impact of Technology Acquisition \& Exploitation onOrganizational Innovation and Organizational Performance in 
Knowledge-Intensive Organizations," EURASIA Journal of Mathematics, Science and Technology Education, vol. 14, pp. 1497-1507, 2018.

P. K. Dimitrios and D. G. Katerina, "Critical factors, food quality management and organizational performance," Food Control, vol. 40, pp. 1-11, 2014.

M. Punniyamoorty, H. Lorentz, P. Mathiyalagan, and G. Lakshmi, "A combined application of structural equation modeling (SEM) and analytic hierarchy process (AHP) in supplier selection," Benchmarking: An International Journal, vol. 19, pp. 70-92, 2012.

S. Joshi, M. Kharat, R. Raut, S. Kamble, and S. Kamble, "To examine the relationships between supplier development practices and supplier-buyer relationship practices from the supplier's perspective," Benchmarking: An International Journal, vol. 24, pp. 1309-1336, 2017.

M. Lashgari, S. J. Sadjadi, and M. Sahihi, "A multi-product, multi-period model to select supplier for deteriorating products while considering uncertainty as well as backorder," Journal of Industrial Engineering International, vol. 15, pp. 93-101, 2018.

S. Banterng, S. Charcrit, S. Theathanick, and K. Kanreutai, "Guidelines for Waste Management in the Plastics Industry in Thailand," BU ACADEMIC REVIEW, vol. 19, pp. 164-176, 2020.

H. Tsai, M. L. Tsai, and J. C. Wang, "Supplier collaboration and new product performance: a contingency model," Industrial Management \& Data Systems, vol. 112, pp. 268-289, 2012.

J. S. Kim, E. Jeon, J. Noh, and J. H. Park, "A Model and an Algorithm for a Large-Scale Sustainable Supplier Selection and Order Allocation Problem," Mathematics, vol. 6, p. 325, 2018.

K. Govindan, D. Kannan, and H. A. Noorul, "Analyzing supplier development criteria for an automobile industry," Industrial Management \& Data Systems, vol. 110, pp. 43-62, 2010

J. S. Randhawa and I. S. Ahuja, "Structural equation modeling for validating impact of 5S implementation on business excellence of manufacturing organizations," International Journal of Quality \& Reliability Management, vol. 34, pp. 1592-1615, 2017.

M. Dawabsheh, A. Hussein, and K. Jermsittiparsert, "The triangular relationship between TQM, organizational excellence and organizational performance: A case of Arab American University Palestine," Management Science Letters, pp. 921-932, 2019.

J. F. Hair, W. C. Black, B. J. Babin, and R. E. Anderson, Multivariate Data Analysis vol. 7: Pearson New International Edition, 2014.

B. Erlan, "The Influence of Interpersonal Trust and Organizational Commitment on Perceived Organizational Performance," Journal of Applied Economics and Business Research, vol. 3, pp. 166-180, 2013.

E. G. Satolo, L. E. d. S. Hiraga, G. A. Goes, and W. L. Lourenzani, "Lean production in agribusiness organizations: multiple case studies in a developing country," International Journal of Lean Six Sigma, vol. 8, pp. 335-358, 2017. 